\title{
As CONEXões E A CirCulação de LiVRos ENTRE AS ORDENS TERCEIRAS FRANCISCANAS NAS DUAS MARGENS Do ATLÂNTICO NO SÉCULO XVIII
}

\author{
THE CONNECTIONS AND CIRCULATION OF BOOKS BETWEEN THE THIRD \\ FRANCISCAN ORDERS IN THE PORTUGUESE EMPIRE \\ OVER THE EIGHTEENTH CENTURY
}

\section{Juliana de Mello Moraes *}

\begin{abstract}
RESUMO
A grande produção e difusão dos livros religiosos durante a Idade Moderna denotaram a essa bibliografia papel relevante naquele período. Além da sua expressividade numérica, as obras religiosas indicavam um leque alargado de preocupações e intenções, visando atender a distintas situações e necessidades tanto dos membros da Igreja quanto dos fiéis. Essa literatura orientava, sobretudo, as práticas religiosas no interior das associações de leigos, tais como irmandades, confrarias e Ordens Terceiras, seja no Reino ou na América portuguesa. A partir do conceito de comunidade de interpretação, cunhado por Roger Chartier, verifica-se a relevância das obras impressas entre os irmãos terceiros franciscanos. Desse modo, a partir da leitura, transcrição paleográfica e análise da documentação produzida pelas Ordens Terceiras franciscanas de Braga (Portugal) e São Paulo (Brasil), ao longo do século XVIII, constatou-se a circularidade dos livros religiosos entre instituições congêneres, bem como os usos destinados a essas obras na conformação de ritos e práticas religiosas.
\end{abstract}

Palavras-chave: Literatura religiosa. Ordem Terceira de São Francisco. Franciscanos.

\section{ABSTRACT}

The great production and diffusion of religious books during the Modern Age denoted to this bibliography a relevant paper in that period. In addition to their numerical expressiveness, religious works indicated a wide range of concerns and intentions, in order to attend to different situations and needs of both members of the Church and of the faithful. This literature guided mainly the religious practices within lay associations, such as brotherhoods, confraternities and Third Orders, whether in the Kingdom or in Portuguese America. From the concept of community of readers, coined by Roger Chartier, it is verified the relevance of the printed works among the Franciscan third brothers. Thus, through the reading, paleographic transcription, and analysis of the documentation produced by the Third Franciscan Orders of Braga (Portugal) and São Paulo (Brazil), throughout the eighteenth century, it was observed the circularity of religious books among similar institutions, as well as the uses destined to these works in the conformation of rites and religious practices.

Keywords: Religious literature. Third Order of Saint Francis. Franciscans.

\footnotetext{
* Doutora em História pela Universidade do Minho, Portugal, com estágio pós-doutoral na Universidade de Lisboa. Bolsa da Fundação para a Ciência e a Tecnologia (FCT-Portugal). Mestrado e graduação em História pela Universidade Federal do Paraná. Professora do quadro permanente da Universidade Regional de Blumenau (FURB). Tem experiência na área de História, com ênfase em História do Brasil Colônia e Portugal (séculos XVII e XVIII), principalmente das instituições, sociabilidades e práticas religiosas e da indumentária na Idade Moderna. E-mail: juliana.mel@gmail.com.
} 


\section{INTRODUÇÃO}

A composição do livro com suas páginas encadernadas, a elaboração de obras com um único autor e o uso da língua vernácula, juntamente com a invenção da imprensa, no século XV, são consideradas as mais significativas inovações no universo da cultura escrita (CHARTIER, 2002, p. 23). Entretanto, dentre tais inovações foi a imprensa a maior dinamizadora da difusão da palavra escrita pelo globo, engendrando objetos por vezes inéditos tanto na forma como no conteúdo. Dentre as variadas temáticas abordadas nos textos impressos destacavam-se, inicialmente, aquelas de cariz religioso. Tanto protestantes como católicos valorizaram e utilizaram as potencialidades do impresso no intuito de difundir seus dogmas morais e doutrinais, bem como promover devoções e práticas religiosas. A importância e a centralidade dessa produção bibliográfica de cunho religioso no universo editorial da época foram destacadas na historiografia, a qual sublinha ainda a relevância dessa literatura no cotidiano das populações até meados do século XVIII (PALOMO, 2011, p. 134).

Muitas instituições católicas ou vinculadas à Igreja, compostas tanto pelo clero (secular ou regular) como por leigos, congregados em associações, colaboraram para a confecção de impressos naquele período. Nesse sentido, cabidos episcopais, ordens religiosas masculinas ou femininas, irmandades, ordens terceiras, entre outras entidades, promoviam a palavra escrita (PALOMO, 2013, p. 63). No entanto, esse conjunto de obras religiosas não era homogêneo e refletia um rol alargado de preocupações e intenções, pois visava atender a distintas situações, necessidades e preocupações tanto dos membros da Igreja quanto dos fiéis. Embora não seja unânime na historiografia a classificação desse vasto universo literário voltado para o religioso, algumas características distinguem as obras, as quais podem ser classificadas, em linhas gerais, como teológicas, litúrgicas, de cânones, de história sagrada, de padres da Igreja ou, ainda, de devoção. Estas últimas destinavam-se a qualquer católico e auxiliavam os fiéis durante suas práticas devocionais.

Dentre as instituições religiosas promotoras da palavra impressa encontra-se a Ordem Terceira de São Francisco. Esta congregava leigos devotos ao santo de Assis e sua Regra foi aprovada pela Santa Sé em 1289. A Regra definia os requisitos de entrada para os irmãos, seus deveres religiosos, as obrigações dos seus administradores e o modo de disciplinar seus associados. Esse documento lhes atribuía um enquadramento jurídico diferente a outras associações de leigos, como irmandades e confrarias. Para adentrar as 
Ordens Terceiras era necessário cumprir um ano de noviciado, período de formação espiritual dos novos membros, e a profissão, cerimônia que marcava a entrada definitiva do indivíduo na instituição (SÃO LUÍS, 1630, p. 5-9).

Desse modo, a Regra compilava disposições fundamentais sobre as práticas religiosas e administrativas, sendo essencial para todos aqueles filiados à Ordem Terceira. No intuito de difundir suas normas, os irmãos terceiros promoviam frequentemente a publicação e a distribuição desse documento, principalmente a partir do século XVII, colaborando para a propagação da palavra impressa naquele período (ARBIOL, 1724, p. 60).

O objetivo desse estudo consiste em analisar a circulação dos livros religiosos, a partir da documentação produzida pelas Ordens Terceiras franciscanas de Braga (Portugal) e São Paulo (Brasil), em especial aqueles de cânones, entre instituições congêneres, bem como os usos destinados a essas obras na conformação de ritos e práticas religiosas ao longo do século XVIII. As obras contendo a Regra são aqui consideradas como cânones, pois era o documento fundamental de ordenamento das associações de irmãos terceiros. A perspectiva adotada busca, portanto, inserir o objeto numa dimensão alargada, uma vez que averigua a circulação dos livros e a leitura em distintos espaços de sociabilidade no império português.

Esse último aspecto, contudo, se caracteriza pela sua fugacidade. Avaliar a leitura e questionar as apropriações daquele que lê constituem-se em tarefas complexas e, por vezes, impossíveis para o historiador diante da precariedade das informações. Porém, a partir do conceito de comunidade de interpretação, a qual compartilha códigos, interesses e categorias (CHARTIER, 1999, p. 124), é plausível verificar a relevância da leitura entre os irmãos terceiros franciscanos. Enquanto uma comunidade de interpretação, as Ordens Terceiras e outros círculos devotos promoviam a leitura de textos compartilhando referências, códigos e interesses. Contudo, apesar das similaridades, os contextos envolvendo a leitura diferiam-se entre os irmãos terceiros no império português, pois as especificidades relacionadas aos distintos espaços geográficos permitem abordar a complexidade da relação entre o livro e seus leitores.

A circulação de obras no interior desses espaços de sociabilidades revelam a difusão de impressos entre as Ordens Terceiras franciscanas tanto no reino quanto na América portuguesa. Apesar da sua relevância para compreender a difusão de impressos e as práticas de leitura da época, essas conexões através da partilha de impressos no interior de círculos devotos, irmandades, confrarias ou Ordens Terceiras ainda são pouco exploradas na historiografia atual (NEVES, 1992; VILLALTA, 1999, ALGRANTI, 2004). 


\section{AS CONEXÕES ENTRE AS ORDENS TERCEIRAS FRANCISCANAS DO REINO E DA AMÉRICA PORTUGUESA}

A Regra ocupava um papel central no cotidiano das Ordens Terceiras franciscanas do império português. Isso porque, ainda que elaborassem estatutos próprios adaptados ao seu contexto, as agremiações seculares não podiam contradizer ou se afastar das determinações da Regra. Nesse sentido, embora possuíssem características similares, devido à obrigatoriedade de seguir as determinações da Regra, facultava-se às associações de irmãos terceiros a hipótese de confecionar estatutos próprios. Estes documentos, elaborados a partir das especificidades locais, permitiam a adaptação das disposições medievais a realidades e momentos diversos.

Contudo, a centralidade da Regra na vivência religiosa dos irmãos terceiros franciscanos revelava-se, por exemplo, na cerimônia da profissão em Braga, na qual os professos deveriam comprometer-se "[...] a guardar em todo o tempo de minha vida [...]" (AOTSFB, 1742, fl. 19) os mandamentos aprovados em 1289. Em São Paulo, a exigência recaía sobre o conhecimento das normas, prescrevendo aos novos irmãos a necessidade de "[...] decorar ou toda ou parte dela [Regra] para exame." (AOTSFSP, 1695, fl. 1). O contato com as disposições do documento ocorriam durante o noviciado, período de um ano no qual os futuros associados eram instruídos nas disposições e práticas da instituição.

Infelizmente, as fontes não disponibilizam informações completas sobre as atividades realizadas durante o noviciado, contudo, parece viável apontar a leitura individual ou coletiva da Regra durante essa fase. A leitura em voz alta, comumente praticada em instituições religiosas femininas, destinava-se a instruir seus membros, sendo, muito provavelmente, utilizada entre os irmãos terceiros para transmitir as disposições normativas aos noviços, principalmente entre os analfabetos (ALGRANTI, 2004, p. 51). Na época, distintos textos eram lidos entre um alargado público permitindo aos não alfabetizados adquirir familiaridade com obras de vários gêneros, incluindo os religiosos (CHARTIER, 1999, p. 124-125). É importante sublinhar ainda o relativo distanciamento entre a palavra escrita e oral, a proximidade entre essas esferas reflete-se na influência exercida pela escrita sobre a expressão oral (BELLINI, 2010, p. 219). A prática recorrente da leitura em voz alta fazia parte do cotidiano de diversas instituições religiosas, sendo fundamental para a difusão do dogma, das devoções, entre outros, devido as altas taxas de analfabetismo da época. 
A necessidade de divulgar e ensinar as disposições normativas, principalmente a Regra, entre os irmãos terceiros proporcionou a elaboração de obras especialmente destinadas a esse objetivo. Na Península Ibérica, a impressão de livros contendo a Regra da Ordem Terceira foi inicialmente incentivada pelos frades franciscanos, contudo os irmãos terceiros também participaram desse movimento desde o século XVII. ${ }^{1}$ As Ordens Terceiras franciscanas em Portugal, como em Braga ou Coimbra, promoveram e financiaram a impressão de livros (VIEIRA, 1688).

Em Braga, os administradores da Ordem Terceira franciscana custearam a impressão de livros e incentivaram a leitura entre os seus associados. Ao longo do século XVIII, a instituição mandou imprimir e encadernar, pelo menos, 650 livros denominados de compêndios. ${ }^{2}$ Embora as indicações disponíveis nas fontes sobre os compêndios careçam de pormenores, tanto a Regra como as informações sobre quais práticas devocionais os irmãos terceiros deveriam realizar para adquirir indulgências contavam nessas obras. Contudo, a própria designação atribuída, ou seja, de compêndios, fornece indícios sobre seu conteúdo e formato. Segundo o dicionário de Bluteau, compêndio significava "resumo, que se faz de algum livro, discurso, ou outra semelhante matéria, cortando tudo o que parece supérfluo e pondo em breves palavras o mais preciso." (BLUTEAU, 1728, p. 416). Nesse sentido, os compêndios das Ordens Terceiras constituíam-se em compilações daquilo que seria considerado essencial para seus associados.

É fundamental avaliar também a materialidade desses livros, pois o seu feitio, dimensão e qualidade consistem em características fundamentais para a análise. Isso porque "a forma que o torna disponível para a leitura também participa da construção do sentido." (CHARTIER, 1999, p. 123).

Infelizmente, devido a atual inexistência das obras editadas pela Ordem Terceira de Braga nos arquivos e bibliotecas portuguesas ou brasileiras, utilizaremos para a análise o Compêndio manual da sempre ilustre, venerável e seráfica Ordem Terceira da Penitência de São Francisco impresso em Coimbra no final do século XVIII. O texto compilava a Regra

\footnotetext{
${ }^{1}$ Nas bibliotecas em Portugal (Biblioteca Nacional de Portugal, Biblioteca Municipal de Braga e Biblioteca Geral de Coimbra) e nos arquivos (Arquivo Nacional da Torre do Tombo, Arquivo Distrital de Braga, Arquivo Distrital do Porto) foram localizadas diversas edições da mesma obra, contendo a Regra, publicadas respectivamente em 1620, 1630 e 1669. Bartolomeu Ribeiro menciona uma edição lisboeta da Regra dos terceiros franciscanos em 1616, entretanto o autor não indica a procedência dessa afirmação. (RIBEIRO, 1952, p. 54).

2 As impressões e encadernações ocorreram entre 1716 e 1780, essas datas correspondem às informações contidas nos livros de despesa da instituição. (AOTSFB, 1710-1760, fls. 5v.; 25; AOTSFB, 1787, fls. 5v.-6, 39, 91, 107).
} 
e as "[...] graças e indulgências de que gozão os filhos desta sagrada Ordem, com algumas advertências a todos elles." (VIEIRA, 1688, s. p.). Apesar de ser uma edição anterior daquelas impressas em Braga, essa obra provavelmente é semelhante aos outros compêndios promovidos pelas associações seculares, pois na Ordem bracarense também traziam as "obrigações e indulgencias que se dão aos irmãos." (AOTSFB, 1775, fl. 72).

Como resumo de obrigações e graças, os compêndios possuíam poucas páginas e eram impressos em formato pequeno, facilitando o transporte pelos seus leitores. De grande sucesso no período, livros com esse suporte podem ser considerados como obras "populares." (CHARTIER, 1999, p. 126). Frequentemente manipulados, lidos e relidos entre os irmãos terceiros, os compêndios tinham preços relativamente baixos, respectivamente 100 réis, em Braga, e 160 réis, em São Paulo. 3

No que se refere ao texto, na introdução o seu autor, João de Seixas Vieira, filiado à Ordem Terceira, indicava claramente sua intenção: "[...] com desejo de que todos os filhos de nossa Santa Ordem possão com pouco trabalho e custo saber a sustância da nossa Santa Regra." (VIEIRA, 1688). Portanto, suporte e texto se adequavam aos objetivos de instruir os irmãos terceiros através da compilação do conteúdo e do formato de baixo custo.

A impressão desse material pela associação bracarense tinha como finalidade tanto de servir aos seus filiados, pois era vendido entre os irmãos terceiros, quanto de atender as demandas de associações congêneres seja de Portugal ou da América. A partir da documentação verifica-se que as Ordens Terceiras de Guimarães e Azurara, freguesia de Vila do Conde, adquiriram através da associação bracarense 50 compêndios cada (AOTSFB, [s. d. a], fl. 144; AOTSFB, 1760-1787, fl. 5v). No entanto, a maior encomenda realizada pela instituição bracarense ocorreu em 1716, quando a mesa administrativa solicitou a encadernação de 400 compêndios, os quais seriam enviados "[...] para os ditos estados do Brasil por conta da Ordem." (AOTSFB, [s. d. a], fl. 63v.). A proibição da instalação de imprensas na América portuguesa (HOLANDA, 1995, p. 119-121) justificava o envio dessas obras para a região, nesse caso para a Ordem Terceira franciscana do Rio de Janeiro.

\footnotetext{
3 Como exemplo comparativo dos valores das obras impressas, pode-se referir para a cidade de Braga o livro descrito nas contas da Ordem Terceira franciscana como Tesouro Seráfico. Este foi adquirido em 1739 pelo valor de 528 réis. (AOTSFB, 1710-1760, s. fl.). Além disso, a partir da historiografia é possível verificar o diminuto preço dos compêndios em comparação com outras funções religiosas da época, tal como as missas. Assim, verifica-se que os preços das missas comuns pagas pela Ordem Terceira franciscana de Braga, durante o século XVIII, sofreram algumas alterações, porém o nunca excederam 120 réis. Em Vila Viçosa, a Santa Casa da Misericórdia, em finais do século XVII, despendia 150 réis por uma missa cantada. Apesar das variações, em Ponte da Barca, a Misericórdia pagou, em média, 110 réis por cada celebração litúrgica ao longo do setecentos. A respeito dos preços das missas em Portugal ler: ARAÚJO, 2000, pp. 303-304; PEREIRA, 2008, pp. 245-246.
} 
A grande quantidade de compêndios, bem como o patrocínio desse material pela Ordem Terceira de Braga, demonstrava o esforço dos irmãos terceiros em difundir as suas normas inclusive no além-mar, revelando também a existência de uma alargada rede de comunicação entre essas associações.

O número expressivo de obras recebido pela Ordem Terceira franciscana do Rio de Janeiro provavelmente decorre do seu papel de intermediária entre as Ordens Terceiras do reino e de outras cidades coloniais, tal como São Paulo. A partir da documentação produzida pela mesa administrativa da instituição paulistana verifica-se a compra regular de compêndios durante a segunda metade do século XVIII. Lamentavelmente, os registros sobre essas aquisições são lacônicos, entretanto, sugerem a existência de vínculos entre a associação do Rio de Janeiro e a Ordem Terceira de São Paulo, pois o rol de despesas relativo a 1781 menciona o pagamento de objetos e compêndios fornecidos pela instituição carioca (AOTFSP, [s. d. b], fl. 69v).

Portanto, as Ordens Terceiras franciscanas investiam na impressão, adquisição e distribuição de obras impressas, indicando a circulação desses materiais entre as duas margens do Atlântico.

\section{A LEITURA E O COTIDIANO: OS IRMÃOS TERCEIROS E A VIVÊNCIA RELIGIOSA}

A Regra para as Ordens Terceiras de São Francisco determinava o essencial para uma vivência religiosa segundo a espiritualidade franciscana, recomendando a prática do jejum, a constante participação das celebrações litúrgicas, a obrigação de rezar as horas canônicas, a necessidade de zelar pelos mortos, de confessar-se regularmente para seus associados, entre outros. Nesse sentido, a busca pela uniformização social, baseada no controle das ações e na prática de distintos exercícios espirituais, marcava a vivência religiosa dos irmãos terceiros franciscanos (DELGADO PAVÓN, 2007, p. 68). No entanto, entre as prescrições e as práticas cotidianas encontram-se proximidades e distanciamentos, a partir dos quais é possível avaliar as leituras efetuadas pelos irmãos terceiros da bibliografia que promoviam. Contudo, se captar os sentidos do leitor individual mostra-se tarefa árdua e pouco viável, a análise das práticas religiosas coletivas permite verificar se os irmãos terceiros atendiam aos desígnios da Regra e, consequentemente, dos compêndios. 
O controle e a fiscalização das práticas religiosas nas Ordens Terceiras era competência dos frades franciscanos, sendo designado um religioso para atender as associações dentro dos limites da sua Província (divisão administrativa da Ordem Primeira de São Francisco). Denominado de comissário visitador ou padre comissário, esse religioso deveria vigiar os irmãos terceiros, especialmente “[...] aquelles que tem officios, instruindo, animando e admoestando a todos em suas obrigaçoens, reprehendendo-os e penitenciandoos pelas faltas, segundo a qualidade delas [...]” (SÃO FRANCISCO, 1684, p. 560).

Na época, o denominado padre comissário, cargo sempre ocupado por um frade franciscano, deveria controlar o conjunto de irmãos seculares, principalmente os administradores das associações. De acordo com a Regra, a visita deveria ser anual e o padre comissário naquele momento avaliava os irmãos terceiros, buscando conhecer os faltosos para lhes dar uma “[...] saudável penitencia pelos excessos cometidos.” (SÃO LUIS, 1630; SÃO LUIS; MONTE OLIVETE, 1669, p. 32). No entanto, o documento esclarece pouco a respeito das formas para exercer esse controle sobre os irmãos, bem como quais ações eram consideradas faltas ou pecados. Todavia, indicava a necessidade de punir os faltosos, primeiramente com penitências e os reincidentes receberiam admoestações do padre comissário e, em último caso, poderiam ser expulsos da associação (SÃO LUIS, 1630; SÃO LUIS; MONTE OLIVETE, 1669, p. 32).

Na Ordem Terceira de Braga o período da visita do padre comissário era denominado de visita geral. Desde finais do século XVII, os registros acerca das visitas são bastante lacônicos, entretanto, a partir de 1756, os seus resultados foram anotados em livro destinado exclusivamente a essas ocasiões (AOTSFB, [s.d. c]). Desse modo, as informações disponibilizadas no livro que continha os resultados das visitas, intitulado o Livro da Vezita, revelam às práticas religiosas dos irmãos e não mencionam falhas, ausências ou irregularidades nas atividades promovidas pela própria associação. Isso porque, a Ordem bracarense, através dos seus administradores, oferecia aos seus associados as celebrações litúrgicas e outras cerimônias de acordo com as disposições normativas, sendo fundamental a realização diária da missa, de acordo com a Regra (VIEIRA, 1688, p. 10).

Segundo os registros das visitas realizadas em Braga, havia entre os irmãos terceiros algum descaso com as missas e outras funções (festas, vias-sacras, procissões, etc.) promovidas pelas Ordens Terceiras. A ausência dos irmãos em acompanhamentos fúnebres, vias-sacras e exercícios espirituais foram salientadas pelo irmão Bernardo Gomes, o qual exigia punição para os faltosos (AOTSFB, [s. d. c], fl. 9). 
Não somente o não comparecimento às celebrações mostrava-se motivo de censura, também a falta de compostura ou sobriedade durante as cerimônias se tornavam motivos de queixas. Um dos inquiridos durante a visita geral em Braga, Barnabé de Araújo Pereira, não hesitou em sublinhar que alguns irmãos, durante as missas, ficavam “[...] jugando nas Lages e fazendo outras conversas menos decentes como elle testemunha terá experimentado.” (AOTSFB, [s. d. c], fl. 7).

As queixas apresentadas durante as visitas gerais na Ordem Terceira de Braga indicam o descumprimento das obrigações impostas pela Regra. As faltas cometidas pelos irmãos terceiros, destacando-se as ausências em cerimônias e comportamento pouco adequado durante as missas, revelam que nem todos os irmãos procuravam atender as normas e distanciavam-se das leituras promovidas pela associação.

Também durante a segunda metade do século XVIII, em São Paulo, foram realizadas visitas pelos padres comissários, sendo os resultados de tais ocasiões transcritos nos livros de atas dos seus administradores. Em 1768, o frade mendicante João Capistrano de São Bento, enquanto padre comissário, ressaltou os problemas relativos às práticas religiosas da Ordem Terceira paulistana, em especial os dias de absolvições. Segundo a Regra os irmãos terceiros deveriam comungar na Páscoa, no Espírito Santo e no Natal, datas fundamentais no calendário litúrgico. Entretanto, a instituição parecia não corresponder às disposições, pois o frade João Capistrano destacou que

[...] encomendamos a todos os nossos Irmãos, e Suditos cuidem em dar hum testemunho publico da Sua christandade praticando virtudes, e frequentando os Sacramentos da Confissão, e Eucharistia, assistindo as [ileg.] de Cada mez, que Costuma esta ordem, e rogamos aos nossos carissimos Irmãos Sacerdotes, por viscera misericordia Dei nostri, nos queirão ajudar, e promover ocupando os confessionarios este acto de piedade [...]. (AOTFSP, [s. d. d], fl. 62).

O padre comissário sublinhou a necessidade da confissão e eucaristia nas datas estipuladas pela Regra, sugerindo o descumprimento desses preceitos na associação paulistana. O pedido direcionado aos sacerdotes também demonstra a falta ou o descaso dos clérigos para atender os fieis durante as funções da Ordem Terceira.

Os distanciamentos referentes às prescrições dos compêndios entre os paulistanos manifestavam-se nas atividades promovidas pela associação, indicando que os seus administradores não seguiam todas as normas, embora conhecessem a Regra e possuíssem compêndios. 
Desse modo, embora utilizassem bibliografia semelhante, as Ordens Terceiras franciscanas adaptavam-se ao seu contexto, tal como se verifica entre as associções de Braga (Portugal) e São Paulo (Brasil). A presença de impressos de cunho normativo e devocional não determinava a priori a homogeneização de instituições congêneres, contudo observa-se o esforço dos religiosos mendicantes na fiscalização das práticas religiosas dos irmãos terceiros tanto no reino quanto no ultramar.

\section{CONSIDERAÇÕES FINAIS}

A complexidade inerente ao processo no qual as obras adquirem significado para seus leitores, incluem, segundo Chartier, três fatores: "[...] o próprio texto, o objeto que comunica o texto e o ato que o aprende." (CHARTIER, 1992, p. 220-221). No entanto, há ainda outro elemento relevante: o contexto mais amplo de inserção e leitura das obras. Apesar da preocupação em difundir os livros através de conexões estabelecidas pelas instituições de distintos pontos do império português, a leitura entre os irmãos terceiros, ainda que valorizada, revela distinções nos significados e na relevância atribuída ao mesmo texto em diferentes sociedades.

Braga, no século XVIII, sede do arcebispado, constituía-se em importante centro religioso possuindo 16 igrejas e 23 capelas, mais a igreja da Sé (FERREIRA; CAPELA, 2002, p. 174). A magnificência da Sé demonstrava a riqueza material e simbólica dos seus arcebispos. Tanto a estrutura administrativa do arcebispado quanto a concentração de igrejas e capelas incentivavam a presença de inúmeros sacerdotes entre a população bracarense. A excessiva quantidade de eclesiásticos na cidade foi destacada inclusive por D. José de Bragança (1741-1756), em 1747, em carta ao Pontífice (FERREIRA; CAPELA, 2002, p. 169).

Portanto, no século XVIII, a cidade de Braga possuía um grande aparelho religioso, marcado pela presença maciça de sacerdotes seculares e regulares, bem como de associações de leigos. Nesse contexto, as instituições religiosas bracarenses, incluindo a Ordem Terceira franciscana, dispunham de muitos padres para a execução das suas celebrações litúrgicas e outras funções, bem como de outros profissionais que prestavam variados serviços necessários à manutenção e administração das instituições, como encadernadores, por exemplo. 
Em contraste, a associação de São Paulo, embora convivesse com outras instituições religiosas, estava imersa num contexto bastante distinto. Desde as descobertas auríferas no interior, no início do século XVIII, ocorreu um crescimento populacional constante, totalizando 435\% entre 1690 e 1765 (MARCÍLIO, 2000, p. 71). Esse aumento da população favoreceu a ampliação do comércio e, paralelamente, do número de associações de leigos (irmandades, confrarias e Ordens Terceiras).

A atuação das ordens religiosas foi fundamental para as mudanças no panorama religioso da cidade, uma vez que as irmandades e as Ordens Terceiras se formaram nas igrejas conventuais, com destaque para os beneditinos, franciscanos e carmelitas. Além dessas mudanças, ao longo do século XVIII, ocorreram importantes alterações na divisão eclesiástica da região. Até 1745, São Paulo fazia parte do bispado do Rio de Janeiro. Nessa data, foram criadas novas divisões eclesiásticas na América portuguesa, estabelecendo-se os bispados de São Paulo e Mariana, e duas prelazias em Goiás e Cuiabá (ZANON, 1999, p. 24). Após a constituição do bispado, a cidade tornou-se sede religiosa da região. Contudo, essas mudanças não favoreceram a melhoria na quantidade e qualidade do corpo eclesiástico, pois quando redigiu a Relação Geral da Diocese de São Paulo, em 1777, o arcebispo D. Manuel da Ressurreição (1771-1789) destacou a falta de sacerdotes e a pouca educação do clero, com seus “[...] poucos livros.” (LUSTOSA, 1975, p. 913).

Portanto, a leitura entre os irmãos terceiros bracarenses e paulistanos, ainda que pertencentes à mesma comunidade de leitores, foi bastante distinta em seus significados. Enquanto a Ordem Terceira de Braga atendia às disposições normativas, convivendo, contudo, com o desvio dos seus associados, a instituição paulistana enfrentava a carência de sacerdotes, tendo dificuldades em atender as determinações da Regra. As práticas religiosas na associação paulistana careciam de atenção, demonstrando que tanto seus administradores quanto seus associados, apesar de conhecerem as disposições normativas através dos compêndios, possuíam dificuldades em efetivar no seu cotidiano o conteúdo das suas leituras.

\section{REFERÊNCIAS}

ALGRANTI, Leila Mezan. Livros de devoção, atos de censura. Ensaios de História do livro e da leitura na América portuguesa (1750-1821). São Paulo: HUCITEC/FAPESP, 2004. 
AOTSFB - ARQUIVO DA ORDEM TERCEIRA DE SÃO FRANCISCO DE BRAGA. Estatutos da Venerável Ordem Terceira da Cidade de Braga, 1742, fl. 19.

AOTSFB - ARQUIVO DA ORDEM TERCEIRA DE SÃO FRANCISCO DE BRAGA. Livro da despesa do síndico da ordem terceira de Braga, 1710-1760, fl. 5V.; 25.

AOTSFB - ARQUIVO DA ORDEM TERCEIRA DE SÃO FRANCISCO DE BRAGA. Livro da despesa do síndico da ordem terceira de Braga, 1760-1787, fl. 5v.-6; 39; 91; 107.

AOTSFB - ARQUIVO DA ORDEM TERCEIRA DE SÃO FRANCISCO DE BRAGA. Livro da Vezita Geral. [s. d. c], fl. 7-9.

AOTSFB - ARQUIVO DA ORDEM TERCEIRA DE SÃO FRANCISCO DE BRAGA. Livro de Termos 2, [s. d. a], fl. 63; 144.

AOTSFB - ARQUIVO DA ORDEM TERCEIRA DE SÃO FRANCISCO DE BRAGA. Livro do inventário geral dos bens imóveis desta venerável ordem, 1775, fl. 72.

AOTSFSP - ARQUIVO DA ORDEM TERCEIRA DE SÃO FRANCISCO DE SÃO PAULO. Livro das recepções, 1695 , fl. 1.

AOTFSP. ARQUIVO DA ORDEM TERCEIRA DE SÃO FRANCISCO DE SÃO PAULO. Livro da formação do patrimônio da capela, [s. d. b], fl. 69v.

AOTFSP. ARQUIVO DA ORDEM TERCEIRA DE SÃO FRANCISCO DE SÃO PAULO. Livro II de termos, [s. d. d], fl. 62.

ARAÚJO, Maria Marta Lobo de. Dar aos pobres e emprestar a Deus: as Misericórdias de Vila Viçosa e Ponte de Lima (séculos XVI-XVIII). Barcelos: Santa Casa da Misericórdia de Vila Viçosa; Santa Casa da Misericórdia de Ponte de Lima, 2000, p. 303-304.

ARBIOL, Antonio. Los terceros hijos de el humano serafin: la Venebrable y Esclarecida Orden Tercera de Nuestro Serafico Patriarca San Francisco. Refierese sus gloriosos principios, regla; leyes, estatutos y Sagrados exercicios; sus frandes excelencias, indulgencias, y Privilegios Apostolicos y las vidas prodigiosas de sus principales santos y santas, para consuelo y aprovechamiento de sus amados hermanos. Zaragoza: Pedro Carreras, 1724.

BELLINI, Lígia. Cultura escrita, oralidade e gênero em conventos portugueses (séculos XVII e XVIII). Tempo, n. 29, 2010.

BLUTEAU, Raphael. Vocabulario portuguez \& latino: aulico, anatomico, architectonico ... Coimbra: Collegio das Artes da Companhia de Jesus, 1712 - 1728. Disponível em: https://digital.bbm.usp.br/handle/bbm/5445. Acesso em: 27 dez. 2019.

CHARTIER, Roger. Leituras e leitores "populares" da Renascença ao Período Clássico. In: CAVALLO, Guglielmo; CHARTIER, Roger (orgs.). História da leitura no mundo ocidental. São Paulo: Editora Ática, 1999. 
CHARTIER, Roger. Os desafios da escrita. São Paulo: Editora UNESP, 2002.

CHARTIER. Texto, impressão, leituras. In: HUNT, Lynn. A nova história cultural. São Paulo: Martins Fontes, 1992.

DELGADO PAVÓN, María Dolores. La Venerable Orden Tercera de San Francisco en el Madrid del siglo XVII (Sociedad confesional, caridad y beneficiencia). 2007. 545 fl. Tese (Doctorado en Historia). Facultad de Filosofia y Letras, Universidad de Alcalá de Henares. Alcalá de Henares, 2007.

FERREIRA, Ana Cunha; CAPELA, José Viriato. Braga Triunfante ao tempo das memórias paroquiais de 1758. Braga: Compolito, 2002.

LUSTOSA, Oscar de Figueiredo. Situação religiosa da Capitania de São Paulo na palavra de seu bispo. D. Frei Manuel da Ressurreição. Revista de História. São Paulo:

Universidade de São Paulo, n. 104, 1975.

MARCÍLIO, Maria Luiza. Crescimento demográfico e evolução agrária paulista 1700-1836. São Paulo: Hucitec, Eduspu, 2000.

NEVES, Lúcia M. Bastos Pereira das. Comércio de livros e censura de ideias: a atividade dos livreiros franceses no Brasil e a vigilância da mesa do Desembargo do Paço. Ler História. Lisboa, n. 23, 1992.

PALOMO, Federico. Cultura religiosa, comunicación y escrita en el mundo ibérico de la Edad Moderna. In: SERRANO MARTÍN, Eliseo (coord.). De la tierra al cielo: líneas recientes de investigación en Historia Moderna. Zaragoza: Institución Fernando el Católico/Universidad de Zaragoza, 2013.

PALOMO, Federico. Misioneros, libros y cultura escrita en Portugal y España durante el siglo XVII. In: CASTELNAU-L'ESTOILE, CH. de; COPETE, M. L., MALDAVSKY, A.; ŽUPANOV, I. G. (eds.). Missions d'évangélisation et circulation des savoirs (XVIe-XVIIIe siècle). Madrid: Collection dela Casa de Velázquez, 2011.

PEREIRA, Maria das Dores de Sousa. Entre ricos e pobres: a actuação da Santa Casa da Misericórdia de Ponte da Barca (1630-1800). Braga: Santa Casa da Misericórdia da Ponte da Barca, 2008.

RIBEIRO, Bartolomeu. Os terceiros franciscanos portugueses: sete séculos da sua história. Braga: Tipografia Missões Franciscanas, 1952.

SÃO FRANCISCO, Luís de. Que contém tudo o que toca a origem, regra, estatutos, cerimonias, privilégios, progressos da sagrada Ordem Terceira de nosso seraphico padre São Francisco. Lisboa: Oficina Miguel Deslandes, 1684.

SÃO LUIS, António de; MONTE OLIVETE, Manoel do. Regra dos Irmãos Terceiros da Sancta, \& veneravel Ordem Terceira da Penitencia, que instituhio o Seraphico P. S. Francisco \& decisoens e resoluçoens de alguas duvidas, sobre o estado da mesma Ordem Terceira. Lisboa: Oficina de João da Costa, 1669. 
SÃO LUÍS, António. Regra dos irmãos seculares da Santa e Venerável Ordem Terceira da Penitência que instituiu o Seraphico padre São Francisco. Lisboa:

Mathias Rodrigues, 1630.

VIEIRA, João de Seixas. Compêndio manual da sempre ilustre, venerável e seráfica Ordem Terceira da Penitência de São Francisco. Coimbra: Oficina de José Ferreira, 1688.

VILLALTA, Luiz Carlos. Os leitores e os usos dos livros na América portuguesa. In: ABREU, Márcia (org.). Leitura, história e história da leitura. São Paulo: FAPESP, 1999.

ZANON, Dalila. A ação dos Bispos e a orientação tridentina em São Paulo (17451796). 1999. 186 p. Dissertação (Mestrado em História). Instituto de Filosofia e Ciências Humanas da Universidade Estadual de Campinas, Campinas, 1999. 